\title{
Aspectos biogeomorfológicos do Atol das Rocas, Atlântico Sul Equatorial
}

\author{
Marcelo de Oliveira Soares ${ }^{1,2}$, Valesca Brasil Lemos', Ruy Kenji Papa de Kikuchi ${ }^{3}$
}

\begin{abstract}
Resumo Análises biogeomorfológicas e de mapeamento das unidades recifais foram realizadas no único Atol do Atlântico Sul Equatorial para a compreensão da dinâmica e do relevo deste recife oceânico. O zoneamento demonstra a presença dos seguintes compartimentos geoambientais: frente recifal, fundo adjacente, margem recifal, platô recifal, anel recifal, resíduos de recifes, laguna recifal, depósito arenoso intermaré, canais, piscinas, poças-de-maré e as ilhas arenosas. Os resultados mostram que uma variedade de organismos atua no Atol em grupos de processos como: controle de erosão nas ilhas arenosas, bioproteção, bioerosão, cimentação de areia carbonática biogênica, produção de sedimentos biodetríticos e bioconstrução. Tais processos biogeomorfológicos geram algumas das características únicas do Atol das Rocas.
\end{abstract}

Palavras-chave: Atol, rocas, biogeomorfologia.

\begin{abstract}
Biogeomorphological aspects of Rocas Atoll, Equatorial South Atlantic. Biogeomorphological analysis and mapping of the reef units in the only Atoll from the Equatorial South Atlantic were held for understanding the dynamics and the relief of this oceanic reef. The zoning shows the presence of the following environmental compartments: reef front, adjacent bottom, reef margin, reef flat, reef ring, reef residues, lagoon, sand flat, reef pass, pools, puddles-of-tide and the sand cays. The results show that a variety of organisms in Atoll that act in processes groups such: control of erosion on sand cays, bioprotection, bioerosion, cementation of biogenic carbonate sand, production of biodetritic sediments and bioconstruction. Such biogeomorphological processes generate some of the unique characteristics of Rocas Atoll.
\end{abstract}

Keywords: Atoll, rocas, biogeomorphology.

INTRODUÇÃO A Biogeomorfologia considera as relações entre os grupos de processos biológicos e geológicos, e o relevo que resulta dessa interação. Essa abordagem é bastante importante, principalmente em recifes coralíneos onde os organismos contribuem na geomorfologia recifal através de processos bioerosivos e de bioconstrução. Assim, em muitos sistemas carbonáticos a relação entre as alterações do relevo e estes processos deve ser considerada. A Biogeomorfologia é considerada um dos campos da Geobiologia (Fig. 1). A Geobiologia é baseada na premissa de que as atividades biológicas e geológicas são integradas, e que as complexas interações entre os sistemas bióticos e abióticos são variáveis na escala temporal e espacial (Spencer \& Viles 2002).

Existem quatro processos biogeomorfológicos fundamentais para a compreensão de recifes coralíneos: a bioerosão, a bioturbação, a bioproteção e a bioconstrução. Tais processos não são mutuamente exclusivos, sendo suas interações variadas, complexas e dinâmicas (Naylor 2005).

Dentro de um ecossistema recifal coralíneo podese perceber que a produção de esqueletos de carbonato de cálcio forma a bioconstrução (o próprio recife). Uma grande quantidade de organismos ataca a estrutura atra- vés de processos ativos de bioerosão (envolvendo desde pequenos microorganismos a animais como peixes e moluscos) produzindo um suprimento de sedimento carbonático que é freqüentemente submetido à bioturbação. O próprio recife possui mecanismos de proteção, como bioproteção, que retarda os processos erosivos. Biofilmes na superfície das rochas podem ter vários papéis na alteração da superfície recifal (Naylor et al. 2002) como em recifes de franja, de barreira e atóis oceânicos.

O Atol das Rocas cresce na parte leste do topo de um monte submarino no Oceano Atlântico (Kikuchi \& Leão 1997). Diversos trabalhos sobre Geomorfologia foram realizados no Atol, dentre os principais podemos citar: Vallaux (1940), Andrade (1959), Ottman (1963), Kikuchi \& Leão (1997), Gherardi \& Bosence (1999), Kikuchi (2002), Gherardi \& Bosence (2005), Soares et al. (2009) e Pereira et al. (2010). Entretanto, estes estudos não realizaram a integração dos processos biológicos aos geológicos como preconiza a emergente área da Biogeomorfologia. Assim, o objetivo deste trabalho é realizar um mapeamento dos compartimentos geoambientais e dos processos biogeomorfológicos no único Atol do Atlântico Sul Equatorial: Atol das Rocas no Nordeste do Brasil.

1 - Universidade Federal do Ceará, Instituto de Ciências do Mar (Labomar), Laboratório de Plâncton e Análise Ambiental, Fortaleza (CE), Brasil. E-mail: marcelosoares@ufc.br

2 - Universidade Federal do Rio Grande do Sul, Instituto de Geociências, Departamento de Paleontologia e Estratigrafia, Porto Alegre (RS), Brasil. E-mail: valesca.lemos@ufrgs.br

3 - Universidade Federal da Bahia, Instituto de Geociências, Departamento de Sedimentologia, Salvador (BA), Brasil.

E-mail: kikuchi@ufba.br 


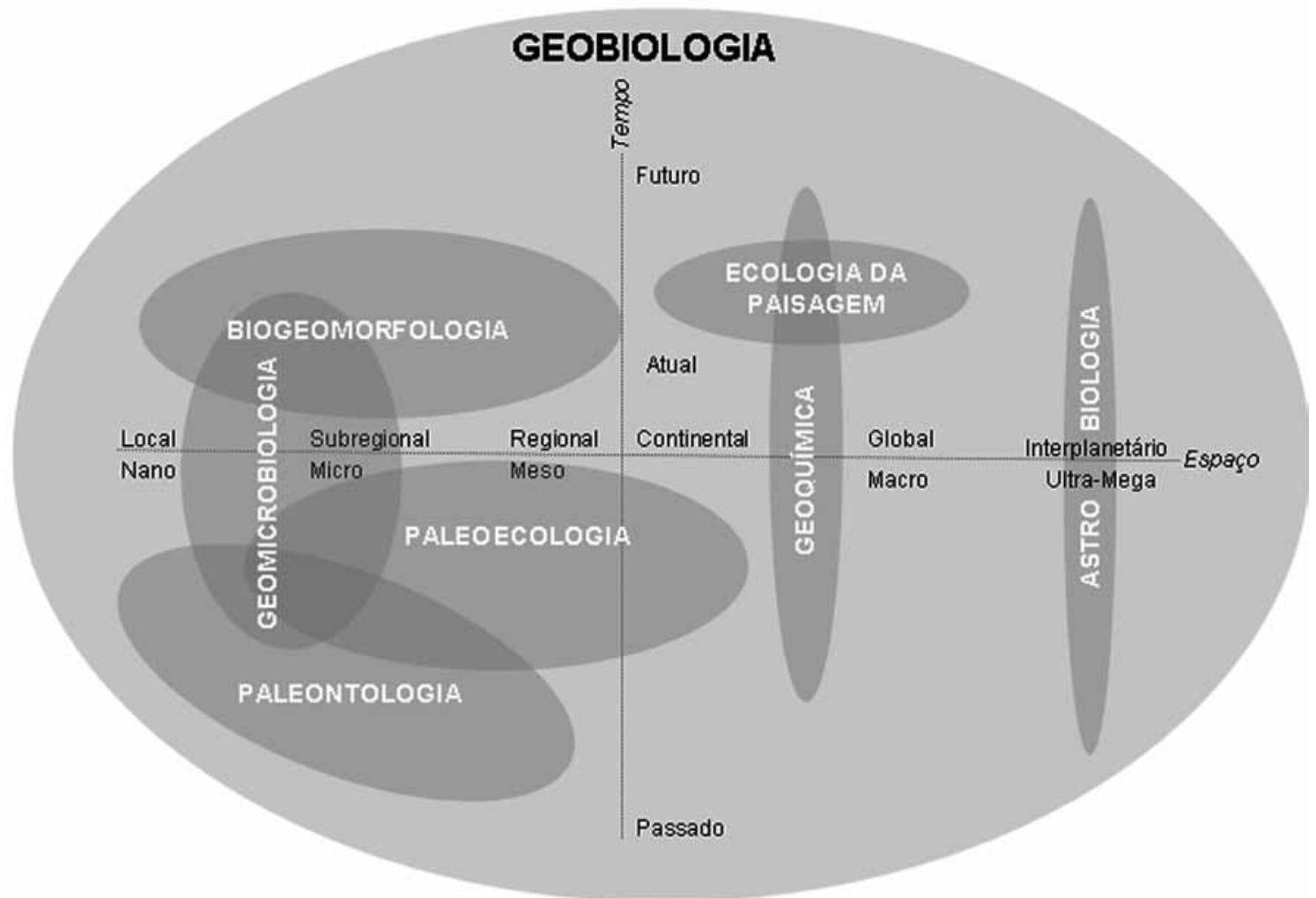

Figura 1 - Áreas de conhecimento da Geobiologia. Modificado de Naylor (2005).

\section{MATERIAIS E MÉTODOS}

Área de estudo A região Equatorial Ocidental do Oceano Atlântico compreende a plataforma continental e planície abissal do Norte do Ceará ao Sul de Pernambuco. Nesta área localiza-se a cadeia norte do Brasil e a cadeia de Fernando de Noronha, da qual também faz parte o Atol das Rocas (Schobbernhaus et al. 1984). Esta região é dominada pela Zona de Convergência Intertropical (ZCIT), que é caracterizada por baixa pressão atmosférica, ventos fracos e alta precipitação, devido à influência dos dois sistemas de alta pressão localizados nas regiões subtropicais dos dois hemisférios, os anticiclones dos Açores ao Norte e o de Santa Helena no Sul (Nimer 1989).

A cadeia de Fernando de Noronha está representada pelo Arquipélago de Fernando de Noronha, Atol das Rocas, e vários bancos submarinos como Grande, Sírius, Guará e o Drina no extremo oeste (Mabesoone $\&$ Coutinho 1970). Esta cadeia situa-se no sopé continental, composta por um segmento de montes, com direção Leste-oeste, que se elevam de profundidades superiores a $4000 \mathrm{~m}$ até a superfície. Estende-se do talude continental ao arquipélago de Fernando de Noronha que é o topo de um monte submarino, cuja base tem um diâmetro de aproximadamente $60 \mathrm{~km}$. Alguns montes caracterizam-se por apresentarem aplainados devido à erosão marinha, formando bancos tipo "guyots" (Larrazábal \& Oliveira 2003). O Atol das Rocas é um dos bancos da cadeia com uma pequena parte emersa (Kikuchi 2002).

O Atol das Rocas está localizado no topo de um monte submarino, cuja base encontra-se a 4000 metros de profundidade no leito oceânico, a $3^{\circ} 51^{\prime} \mathrm{S}$ Latitude e $33^{\circ} 49^{\prime} \mathrm{W}$ Longitude, distante $266 \mathrm{~km}$ da cidade de Natal e a $150 \mathrm{~km}$ a oeste do arquipélago de Fernando de Noronha, no Nordeste Brasileiro (Echeverría \& Pires 1997, Kikuchi \& Leão 1997). O atol é composto, principalmente, por algas calcárias incrustantes, foraminíferos e moluscos vermetídeos (Gherardi \& Bosence 1999; Soares et al. 2009).

Os ventos de leste e sudeste são predominantes ao longo do ano com uma freqüência de $45 \%$ e velocidades variando entre 6,0 a $10,0 \mathrm{~m} / \mathrm{s}$. Estes parâmetros possuem relativa sazonalidade: nos meses de inverno (de junho a agosto), observa-se $35 \%$ para ventos de SE e $15 \%$ para E, com velocidades variando entre 11,0 e $15,0 \mathrm{~m} / \mathrm{s}$; para o verão (de dezembro a abril), a freqüência fica em torno de $20 \%$ para os ventos SE e E, com velocidade freqüentemente acima de 20,0 m/s (Kikuchi \& Leão 1997).

A temperatura da água do mar possui média de $27,0^{\circ} \mathrm{C}$, podendo chegar a $42{ }^{\circ} \mathrm{C}$ nas piscinas, com salinidade na superfície variando entre 34 e 37 . O regime de marés é semidiurno e mesotidal, com uma variação máxima de $2,7 \mathrm{~m}$, deixando exposto o platô recifal em marés baixas de sizígia (Gherardi \& Bosence 1999).

Trabalhos de campo e laboratório As análises de campo foram realizadas na REBIO (Reserva Biológica) Atol das Rocas durante o período de 30 de janeiro a 25 de fevereiro de 2008. O tratamento do aspecto geral do Atol requereu diferentes etapas como interpretação de imagens aéreas e análise das características biogeomorfológicas.

As observações do recife foram efetuadas du- 
rante caminhadas no platô recifal, exposto nas marés baixas, e durante mergulhos, em apnéia e autônomo, nas partes submersas. Os pontos de observação foram inicialmente plotados em mapas e georeferenciados. Os dados anotados nesses pontos de descrição foram: os compartimentos geomorfológicos do Atol; os organismos bioconstrutores, bioerosivos, bioprotetores e bioturbadores dos sedimentos no Atol. Esses dados foram completados com documentação fotográfica detalhada e com amostragens sedimentares e do recife.

As observações foram feitas principalmente com equipamento de respiração autônoma "SCUBA" e também em apnéia ou "snorkeling". Os dados foram registrados a lápis em placas de PVC branco quando referentes a dados subaquáticos. Na parte aérea foi realizados mapeamentos e perfis geológicos utilizando GPS.

RESULTADOS E DISCUSSÕES O zoneamento geomorfológico demonstra a presença de diferentes compartimentos geoambientais no Atol das Rocas como: frente recifal, margem recifal, fundo adjacente, platô recifal, anel recifal, resíduos de recifes, laguna recifal, depósito arenoso intermaré, canais, piscinas, poças-de-maré e as ilhas arenosas de areia carbonática biogênica (Figs. 2 e 3).

Os táxons encontrados no recife oceânico apresentaram diferentes atividades incluindo processos biogeomorfológicos como estruturas de bioturbação, bioerosão recifal, proteção contra erosão, cimentação de areia carbonática, produção de sedimentos biodetríticos, bioproteção e bioconstrução recifal (Tab. 1 e Fig. 4).

Segue uma descrição dos principais compartimentos geomorfológicos no zoneamento e os principais efeitos biogeomorfológicos dos organismos na estrutura do Atol das Rocas.

Frente Recifal Na parte externa do Recife, contíguo à frente recifal, o fundo oceânico foi denominado por Kikuchi (2002) como fundo adjacente, sendo descrito em associação à frente recifal. A frente recifal estendese da borda externa da margem recifal (Fig. 5A), que na baixa-mar fica cerca de $1,5 \mathrm{~m}$ acima do nível médio do oceano, até o fundo adjacente, em profundidades inferiores a $10 \mathrm{~m}$. A parede da frente recifal inicia-se como uma escarpa abrupta de cerca de 2 metros. Pode-se observar a continuidade do spur-and-groove ao longo da frente recifal (Fig. 5C). Com o afastamento do atol

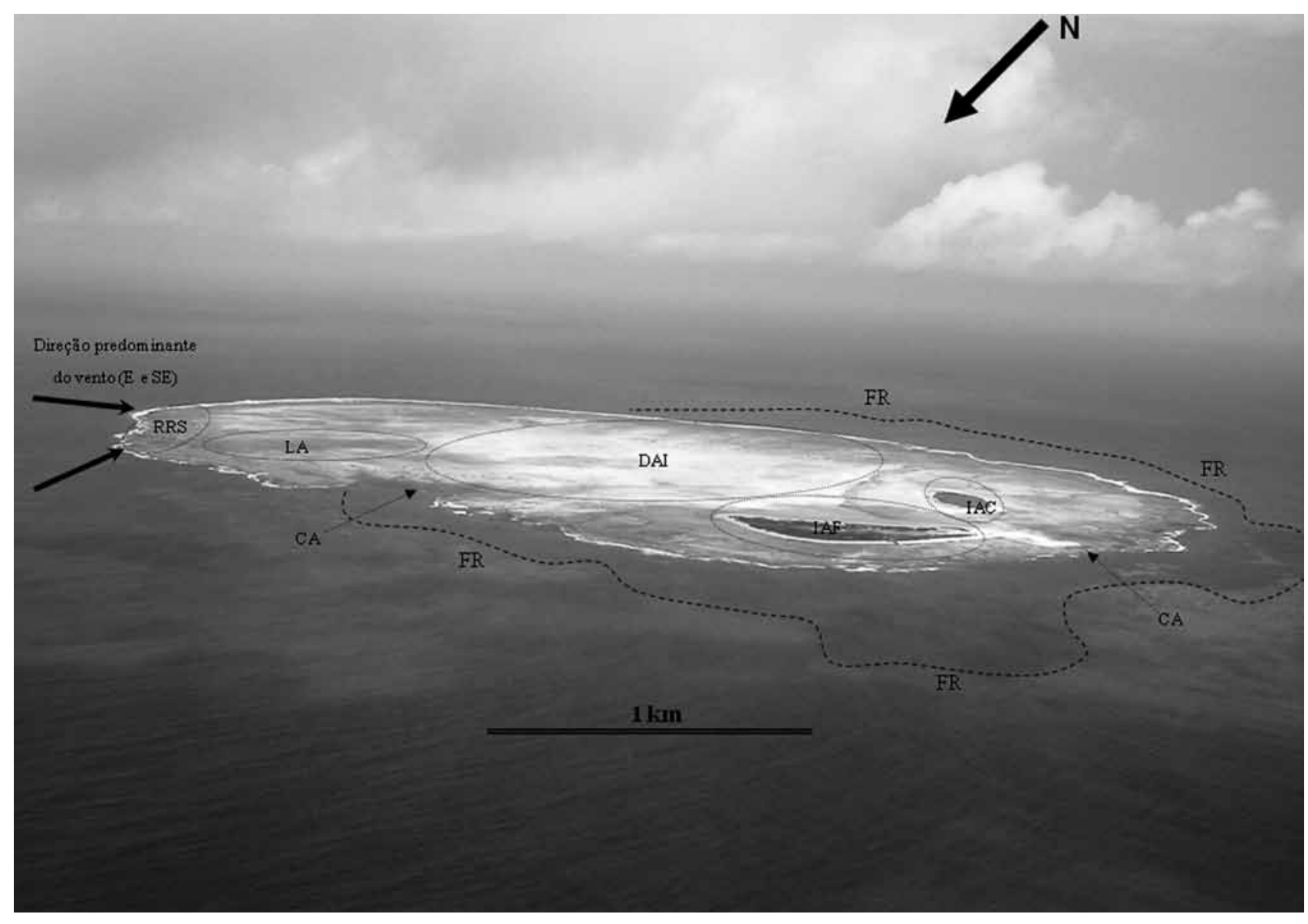

Figura 2 - Mapa geomorfológico elaborado a partir de Aerofotografia do Atol das Rocas (Atlântico Sul Ocidental) demonstrando a forma elipsóide, as ilhas arenosas a sotavento (IA) e o pequeno tamanho da laguna (LA) que não ocorre na área central. Os canais (CA), Frente recifal (FR), Depósito Arenoso Intermaré (DAI) e a área do Resíduos de Recifes (RRS) são outras zonas geomorfológicas. Mapa modificado a partir da foto da Força Aérea Brasileira (FAB) retirada nas atividades de campo em janeiro de 2008 em maré baixa de sizígia. 


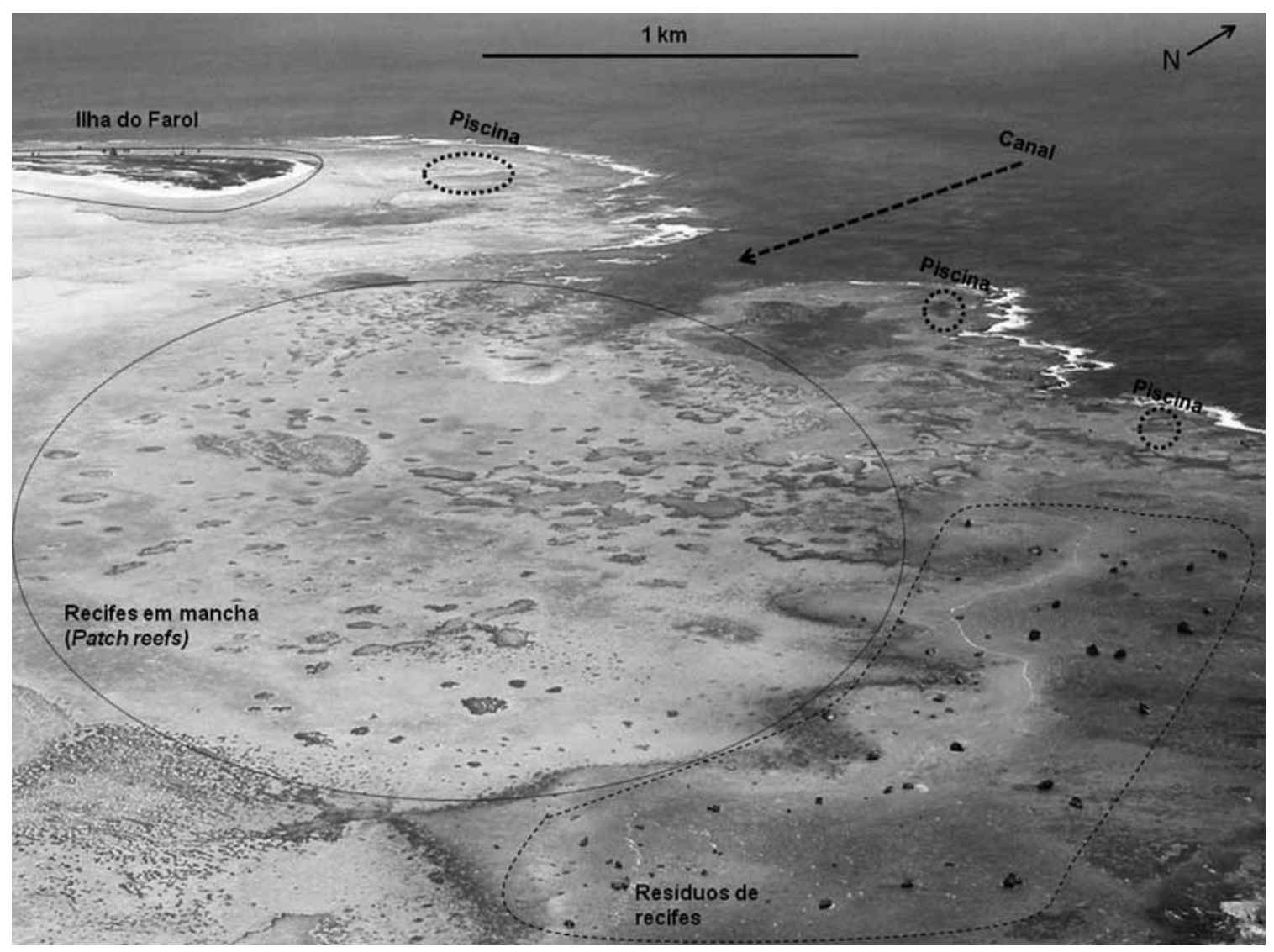

Figura 3 - Aerofotografia do Atol das Rocas (NE, Brasil) mostrando a Zona onde ocorrem Resíduos de Recifes, piscinas, recifes em mancha, a ilha do Farol a sotavento e o maior canal que liga a área interna do Atol à zona adjacente do Oceano Atlântico. Foto da Força Aérea Brasileira (FAB) obtida em janeiro de 2008 em maré baixa de sizígia.

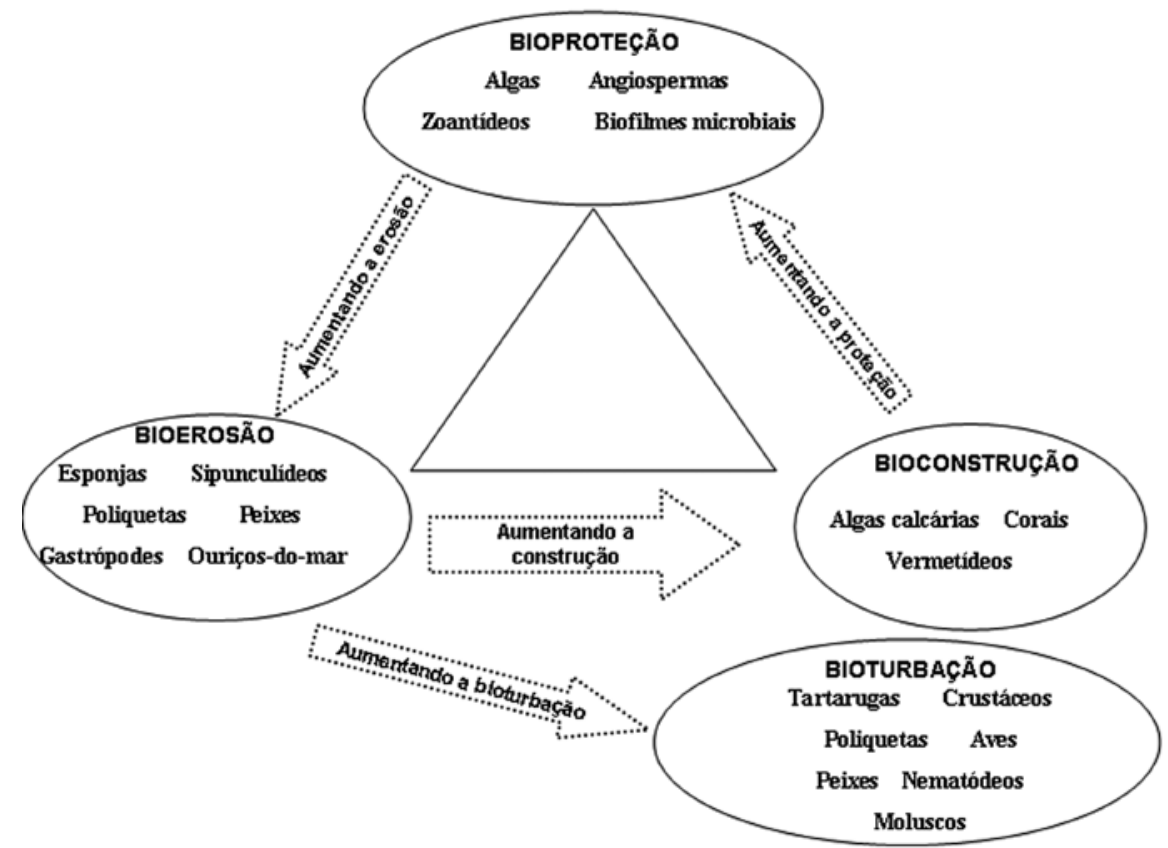

Figura 4 - Interação entre diferentes processos biogeomorfológicos no Atol das Rocas. Tal figura representa apenas parte dos importantes componentes dos sistemas biogeomorfológicos do Atol e não ilustra os processos "inorgânicos" da superficie do recife ou a interação destes com os bioprocessos. Os processos exógenos (modos inorgânicos de erosão, transporte e deposição) e processos endógenos afetam os sistemas biogeomorfológicos do Atol das Rocas. 
Tabela 1 - Principais táxons e seu papel biogeomorfológico no Atol das Rocas, Atlântico Sul Equatorial. Abreviaturas: $\mathrm{Fr}$ (Frente recifal), $\mathrm{Fa}$ (Fundo Adjacente), $\mathrm{Mr}$ (Margem recifal), $\mathrm{Pr}$ (Parede Recifal), Ar (Anel recifal), Rrs (Resíduos de Recifes), Dai (Depósito arenoso intermaré), Ca (Canais), Pi (Piscinas), Ia (Ilhas arenosas), La (Laguna).

\begin{tabular}{|c|c|c|c|}
\hline Organismo & Táxon & Função Biogeomorfológica & $\begin{array}{c}\text { Compartimentos geoambientais } \\
\text { de ocorrência }\end{array}$ \\
\hline $\begin{array}{l}\text { Planta terrestre } \\
\text { (Angiosperma) }\end{array}$ & Sesuvium portulacastrum & $\begin{array}{l}\text { Fixação das ilhas arenosas no pós-praia a } \\
\text { sotavento e proteção contra erosão }\end{array}$ & Ia \\
\hline $\begin{array}{l}\text { Planta terrestre } \\
\text { (Angiosperma) }\end{array}$ & Portulaca oleracea & $\begin{array}{c}\text { Fixação das ilhas arenosas no pós-praia a } \\
\text { sotavento e proteção contra erosão }\end{array}$ & Ia \\
\hline $\begin{array}{l}\text { Planta terrestre } \\
\text { (Angiosperma) }\end{array}$ & Cyperus ligularis & $\begin{array}{c}\text { Fixação das ilhas arenosas no pós-praia a } \\
\text { sotavento e proteção contra erosão }\end{array}$ & Ia \\
\hline Macroalga & Digenia simplex & Bioproteção da estrutura recifal & Fr, Mr, Pr, Ar, Ca, Pi, La \\
\hline Macroalga & Gelidiella acerosa & Bioproteção da estrutura recifal & Fr, Mr, Pr, Ar, Ca, Pi, La \\
\hline $\begin{array}{l}\text { Corais moles (Cnidaria: } \\
\text { Zoanthidea) } \\
\end{array}$ & Zoanthus sociatus & Bioproteção da estrutura recifal & Ar, Pi, Pr \\
\hline $\begin{array}{l}\text { Corais moles (Cnidaria: } \\
\text { Zoanthidea) } \\
\end{array}$ & Palythoa caribaeorum & Bioproteção da estrutura recifal & Ar, Pi, Pr \\
\hline Esponja (Porifera) & Cliona spp. & Bioerosão & Fr, Mr, Pr, Ar, Ca, Pi, La \\
\hline Sipunculídeos & Sipuncula & Bioerosão & Fr, Mr, Pr, Ar, Ca, Pi, La \\
\hline Poliquetos (Annelida) & Polychaeta & Bioerosão & Fr, Mr, Pr, Ar, Ca, Pi, La, Daí \\
\hline $\begin{array}{l}\text { Peixes (Pisces: } \\
\text { Actinopterygii) }\end{array}$ & Sparisoma spp. & Bioerosão & Fr, Mr, Pr, Ar, Ca, Pi, La, Dai, Fa \\
\hline $\begin{array}{l}\text { Peixes (Pisces: } \\
\text { Actinopterygii) }\end{array}$ & Acanthurus spp. & Bioerosão & Fr, Mr, Pr, Ar, Ca, Pi, La, Dai, Fa \\
\hline $\begin{array}{l}\text { Molusco (Mollusca: } \\
\text { Gastropoda) }\end{array}$ & Fissurella sp. & Bioerosão & Fr, Mr, Pr, Ar, Ca, Pi, La, Dai, \\
\hline Alga calcárea & Porolython pachydermum & Bioconstrução carbonática & Fr, Mr, Pr, Ar, Ca, Pi, La, Fa \\
\hline Alga calcárea & Lythoporella sp. & Bioconstrução carbonática & $\mathrm{Fr}, \mathrm{Mr}, \mathrm{Pr}, \mathrm{Ar}, \mathrm{Ca}, \mathrm{Pi}, \mathrm{La}, \mathrm{Fa}$ \\
\hline Alga calcárea & Lythophyllum sp. & Bioconstrução carbonática & Fr, Mr, Pr, Ar, Ca, Pi, La, Fa \\
\hline Alga calcárea & Sporolython sp. & Bioconstrução carbonática & Fr, Mr, Pr, Ar, Ca, Pi, La, Fa \\
\hline Foraminífero & Homotrema rubrum & Bioconstrução carbonática & Fr, Mr, Pr, Ar, Ca, Pi, La, Fa \\
\hline $\begin{array}{l}\text { Vermetídeos (Mollusca: } \\
\text { Gastropoda) }\end{array}$ & Dendropoma sp. & Bioconstrução carbonática & Fr, Mr, Pr, Ar, Ca, Pi, La, Fa \\
\hline $\begin{array}{l}\text { Vermetídeos (Mollusca: } \\
\text { Gastropoda) }\end{array}$ & Petaloconchus sp. & Bioconstrução carbonática & Fr, Mr, Pr, Ar, Ca, Pi, La, Fa \\
\hline $\begin{array}{l}\text { Coral escleractineo } \\
\text { (Cnidaria) }\end{array}$ & Siderastrea stellata & Bioconstrução carbonática & Fr, Mr, Pr, Ar, Ca, Pi, La, Fa \\
\hline $\begin{array}{l}\text { Coral escleractíneo } \\
\text { (Cnidaria) }\end{array}$ & Favia gravida & Bioconstrução carbonática & Fr, Mr, $\mathrm{Pr}, \mathrm{Ar}, \mathrm{Ca}, \mathrm{Pi}, \mathrm{La}, \mathrm{Fa}$ \\
\hline $\begin{array}{l}\text { Coral escleractíneo } \\
\text { (Cnidaria) }\end{array}$ & Porites sp. & Bioconstrução carbonática & Fr, Mr, Pr, Ar, Ca, Pi, La, Fa \\
\hline $\begin{array}{l}\text { Chelonya: Testudines } \\
\text { (Cnidaria) } \\
\end{array}$ & Chelonya midas & Bioturbação & Ia, Dai \\
\hline $\begin{array}{c}\text { Caranguejo (Crustacea: } \\
\text { Brachyura) } \\
\end{array}$ & Gecarcinus lagostoma & Bioturbação & Ia \\
\hline Aves: Laridae & Anous stolidus & Bioturbação & Ia \\
\hline Aves: Sulidae & Sula sp. & Bioturbação & Ia \\
\hline Annelida: Polychaeta & Polychaeta spp. & Bioturbação & Ia, Dai \\
\hline Arthropoda Crustacea & Arthropoda sp.1 & Bioturbação & Ia \\
\hline Arthropoda: Crustacea & Arthropoda sp. 2 & Bioturbação & Ia, Dai \\
\hline Arthropoda: Crustacea & Arthropoda sp.3 & Bioturbação & Ia, Dai \\
\hline $\begin{array}{l}\text { Peixes (Pisces: } \\
\text { Actinopterygii) }\end{array}$ & Malacanthus plumieri & Bioturbação & Fr, Mr, Pr, Ar, Ca, Pi, La, Dai, Fa \\
\hline $\begin{array}{l}\text { Caranguejo (Crustacea: } \\
\text { Brachyura) }\end{array}$ & Goniopsis cruentata & Bioturbação & Ia \\
\hline
\end{tabular}




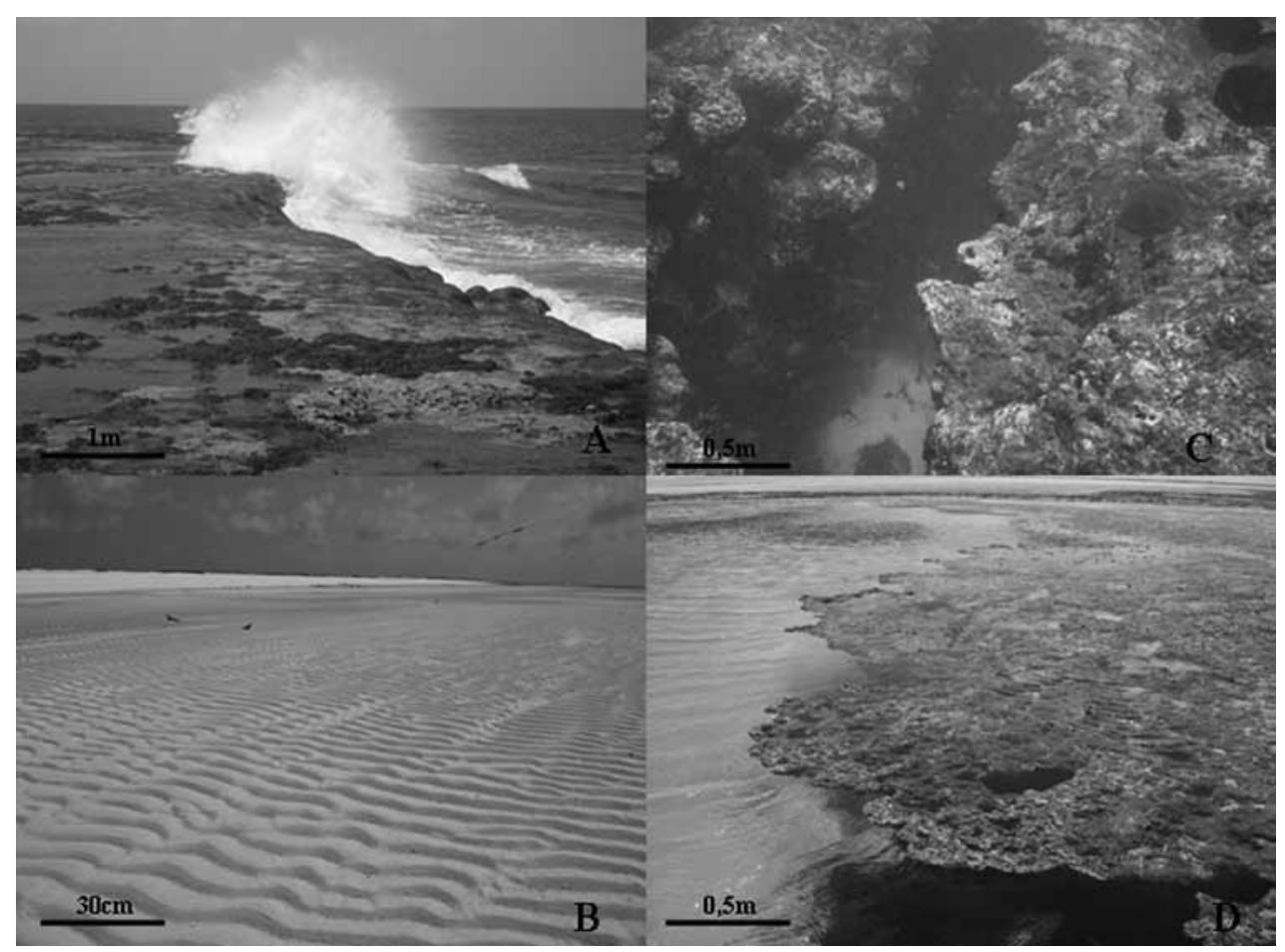

Figura 5 - Zonas geomorfológicas no Atol das Rocas (Atlântico Sul Equatorial). A) Frente recifal do Atol das Rocas, NE do Brasil. Zona de alta energia do Recife oceânico. B) Depósito arenoso intermarés do Atol das Rocas, NE do Brasil, exibindo "ripple marks", pela ação das marés. Foto obtida na maré baixa. C). Foto subaquática da frente recifal na parte subaquática do Atol das Rocas, NE do Brasil mostrando ranhura como continuação do sistema "spur-and-groove" e acumulação de sedimento bioclástico no fundo. Profundidade: 10 metros. D) Piscina no Atol das Rocas mostrando a estrutura de "overhangs" (palas-de-boné) nas suas margens.

ocorre a diminuição da estrutura recifal e o aumento de áreas de sedimento arenoso-cascalhoso em áreas de fendas na estrutura rochosa. Verificou-se a presença de fortes correntes de fundo próximo à frente recifal podendose caracterizar a zona como de alta energia no recife.

Kikuchi \& Leão (1997) comentam que a frente recifal é mais extensa na porção $\mathrm{W}$ do atol e sua extensão horizontal a partir da borda externa da margem recifal pode atingir até $600 \mathrm{~m}$ com declividade aproximada de $1^{\circ} 15^{\prime}$. Ainda na porção $\mathrm{W}$, apresenta um padrão denteado perpendicular ao perímetro do recife. Segundo Guilcher (1988) esta feição é bem comum em recifes Indo-Pacíficos e Caribenhos. Kikuchi (2002) observou que, em determinados locais, no lado NW e N-NE pode-se verificar que o denteamento é uma sucessão de colunas que coalescem formando o topo recifal e que são gradativamente menores à medida que se afastam da borda do recife. Já as zonas intermediárias, intercolunares, estão preenchidas por sedimentos arenosos (Ottman 1963, Kikuchi \& Leão 1997). Nos lados NE e SE, a frente recifal encontra-se com topografia bem abrupta constituindo uma escarpa de aproximadamente $10 \mathrm{~m}$ de profundidade, sendo que a partir deste ponto até $15 \mathrm{~m}$, freqüentemente encontram-se depósitos sedimentares grossos de sopé de encosta.

Nos lados SW e NW observando-se a superfície da frente recifal encontram-se feições aproximadamente hemisféricas, sendo recobertas com algas clorofíceas. Diversos corais escleractíneos como Siderastrea stellata, Porites sp. e Montastrea cavernosa são encontrados nesse compartimento geoambiental atuando na bioconstrução, porém comumente sua distribuição é esparsa.

Nesta zona biogeomorfológica atuam macroalgas e zoantídeos no processo de bioproteção contra o impacto das ondas e correntes, além da atuação de organismos bioerosivos como os peixes, esponjas, sipunculídeos e poliquetas. Uma forte bioconstrução de algas calcárias e de corais tem um forte papel biogeomorfológico acrescentando carbonato de cálcio a estrutura recifal.

Fundo Adjacente No Atol das Rocas, mais especificamente na sua porção oeste, o fundo caracteriza-se por um substrato de areia carbonática com presença de elevações de construções recifais isoladas com aproximadamente de $1,5 \mathrm{~m}$ de altura com forte papel da construção na biogeomorfologia. Segundo Kikuchi (2002) as dimensões horizontais desses recifes podem variar de menos de $1 \mathrm{~m}$ até cerca de $5 \mathrm{~m}$ de largura e comprimento de até $10 \mathrm{~m}$. O mesmo autor observa que esses recifes são alongados na direção E-W e são prolongamentos da feição denteada da frente recifal. Estudos sedimentológicos (Kikuchi 2002) indicaram pra super- 
fície arenosa a presença de fácies de formas de leito onduladas com cristas lineares. No lado E e SE a presença de um terraço de topografia bastante plana e horizontal, a uma profundidade de $15 \mathrm{~m}$, é possivelmente o topo de plataforma que serve de substrato ao Atol das Rocas.

Neste compartimento há pouca ação de organismos bioprotetores devido à dificuldade de fixação das larvas e de sobrevivência destas. Há impacto significativo de peixes bioerosivos, principalmente do gênero Sparisoma spp. que tem atuação direta na bioerosão, pois atuam como organismos raspadores retirando fragmentos da estrutura recifal.

Margem Recifal Acompanhando a borda externa do recife observa-se a margem constituída de um alinhamento de convexidades. A largura é variável podendo atingir cerca de $5 \mathrm{~m}$, e altura de até $0,5 \mathrm{~m}$ acima da superfície contígua do platô recifal (Kikuchi 2002). Um aspecto biogeomorfológico fundamental é a presença da crista algálica, construída por algas coralináceas e gastrópodes vermetídeos (bioconstrutores) que apresenta um aspecto geral bem maciço, feição praticamente contínua e que forma a margem recifal. Duran- te os períodos de baixa-mar a margem fica exposta ao ambiente aéreo. A área é geomorfologicamente e funcionalmente muito importante devido dissipar a energia das ondas vindas do oceano Atlântico. As macroalgas têm papel fundamental em recobrir a superfície recifal e diminuir os processos denudacionais.

Platô recifal Tal compartimento geoambiental é caracterizado por uma superfície aplainada da parte superior e interna do recife, estando contígua à margem recifal, e fica acima do nível do mar durante os períodos de baixa-mar. No platô recifal se encontram feições como os canais, poças-de-maré, as piscinas e as ilhas arenosas. Segundo Kikuchi \& Leão (1997), Kikuchi (2002) e Soares et al. (2009) o platô compreende ainda o anel recifal e o depósito arenoso (fácies sedimentar mais comum na porção interna do recife). No platô recifal é bastante comum à presença das macroalgas Digenia simplex e Gelidiella acerosa que atuam na bioproteção (Fig. 6B).

Anel Recifal Na faixa periférica bioconstruída que delimita a parte interna do recife encontra-se o anel recifal.

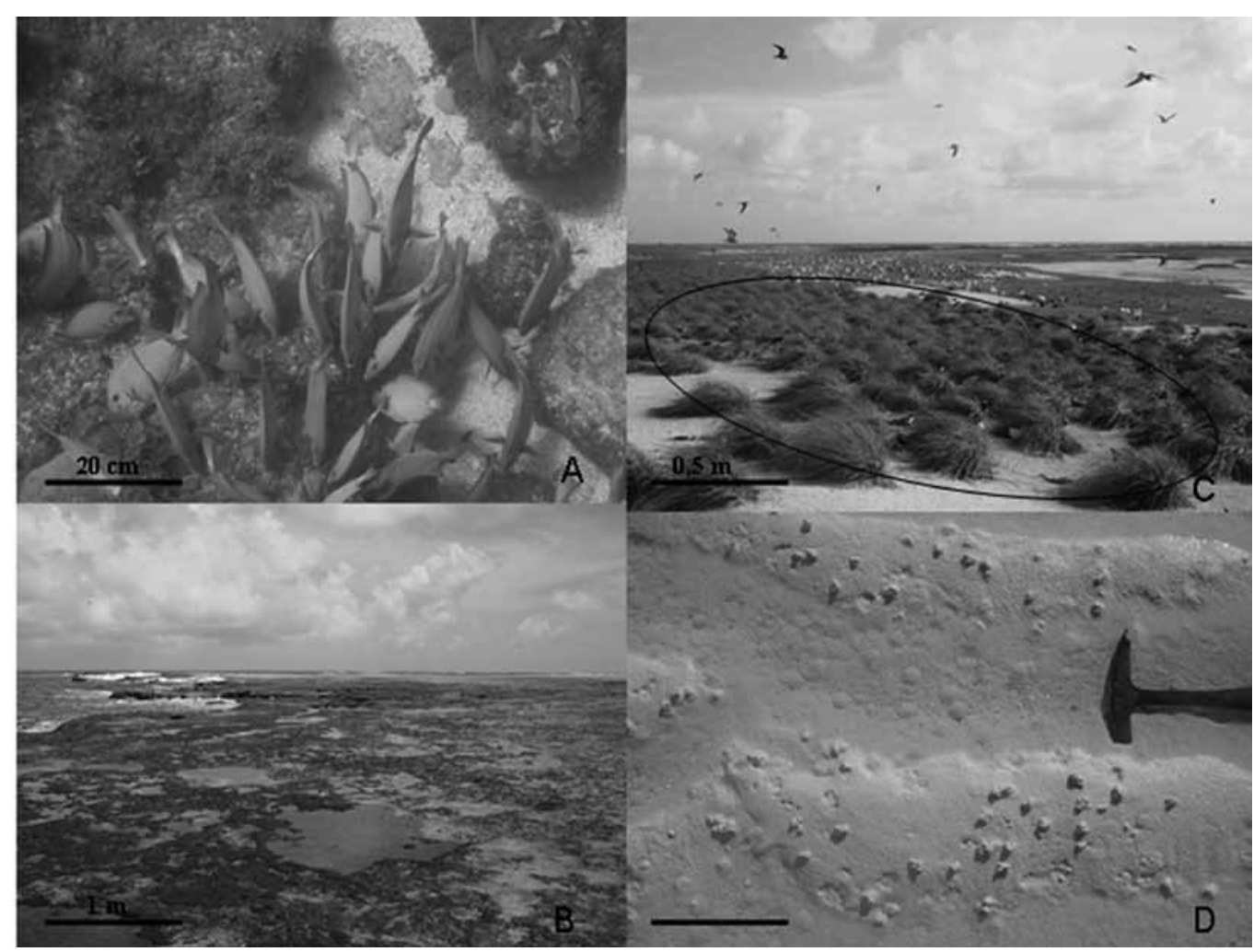

Figura 6 - Aspectos biogeomorfológicos no Atol das Rocas nas piscinas, platô recifal, ilhas arenosas e depósito arenoso intermaré. A) Peixes-cirurgiões Acanthurus chirurgus atuam de maneira indireta na bioerosão ao diminuir a bioproteção proporcionada pelas macroalgas. Observar sedimento carbonático depositado no fundo entre os recifes em mancha (patch-reefs) de uma piscina. B) Platô recifal com forte cobertura de macroalgas que proporcionam uma bioproteção a estrutura recifal. C) Vegetação formada por Cyperus ligularis (marcada pela elipse) que auxilia no processo de fixação das areias carbonáticas bioclásticas para formação das ilhas arenosas e na proteção contra erosão. D) Bioturbação de poliquetas (formas globulares) no sedimento carbonático do Depósito Arenoso Intermaré. 
Segundo Kikuchi (2002), Soares et al. (2009) e Pereira et al. (2010) o anel é circundado pela margem recifal e circunscreve o depósito arenoso e a laguna. Pode-se subdividir o anel nos arcos a sotavento e barlavento.

Pode-se observar em relação aos aspectos de bioconstrução que algas coralinas incrustantes (Lythoporella sp., Lythophyllum sp., Sporolython sp. e, principalmente, Porolython pachydermum) e gastrópodes vermetídeos são os principais contribuintes da massa carbonática (Fig. 7A). O crescimento destes bioconstrutores ocorre na forma de cristas algáceas lineares, com alguns centímetros de largura, contínuas ou segmentadas. $\mathrm{O}$ entrelaçamento das cristas algáceas leva à formação de poças-de-maré com presença de corais escleractíneos como Favia gravida e Siderastrea stella$t a$ e de depósitos arenosos. Estas feições sedimentares apresentam-se perpendiculares à direção da movimentação da corrente que atravessa o recife.

Resíduos de Recifes No setor a barlavento, nas posições E e SE do recife, encontram-se os cálices ou "rocas", que são resquícios de uma estrutura mais elevada do recife em níveis de mar alto. Essas estruturas residu- ais são oriundas de um paleorecife que durante a descida do nível do mar sofreu processos erosivos e de intemperismo constituindo uma plataforma de abrasão pretérita. Tais cálices possuem algas coralinas incrustantes, gastrópodes vermetídeos e o foraminífero Homotrema rubrum atuando na bioconstrução. Essas rocas (ou cálices) são evidências de uma posição holocênica de nível eustático mais elevado do que o atual (Kikuchi 2002; Soares et al. 2009) e dos processos biogeomorfológicos holocênicos.

Depósito Arenoso Intermaré Andrade (1959), Ottman (1963) comentam sobre a presença de uma "laguna muito rasa", já Kikuchi (2002) aborda que a maior parte deste compartimento geoambiental pode ser descrito como depósito arenoso. O termo depósito arenoso intermaré faz menção à presença de sedimento inconsolidado com presença de formas de leito onduladas ("ripple marks") derivados da dinâmica da maré (Fig. 5B). Notase a presença de uma marcante assimetria, com cristas descontínuas e arqueadas. Kikuchi (2002) aborda que a transição do anel recifal para o depósito arenoso ocorre de maneira gradual, em termos de profundidade. $\mathrm{Na}$ parte NE o anel recifal passa diretamente para a laguna,

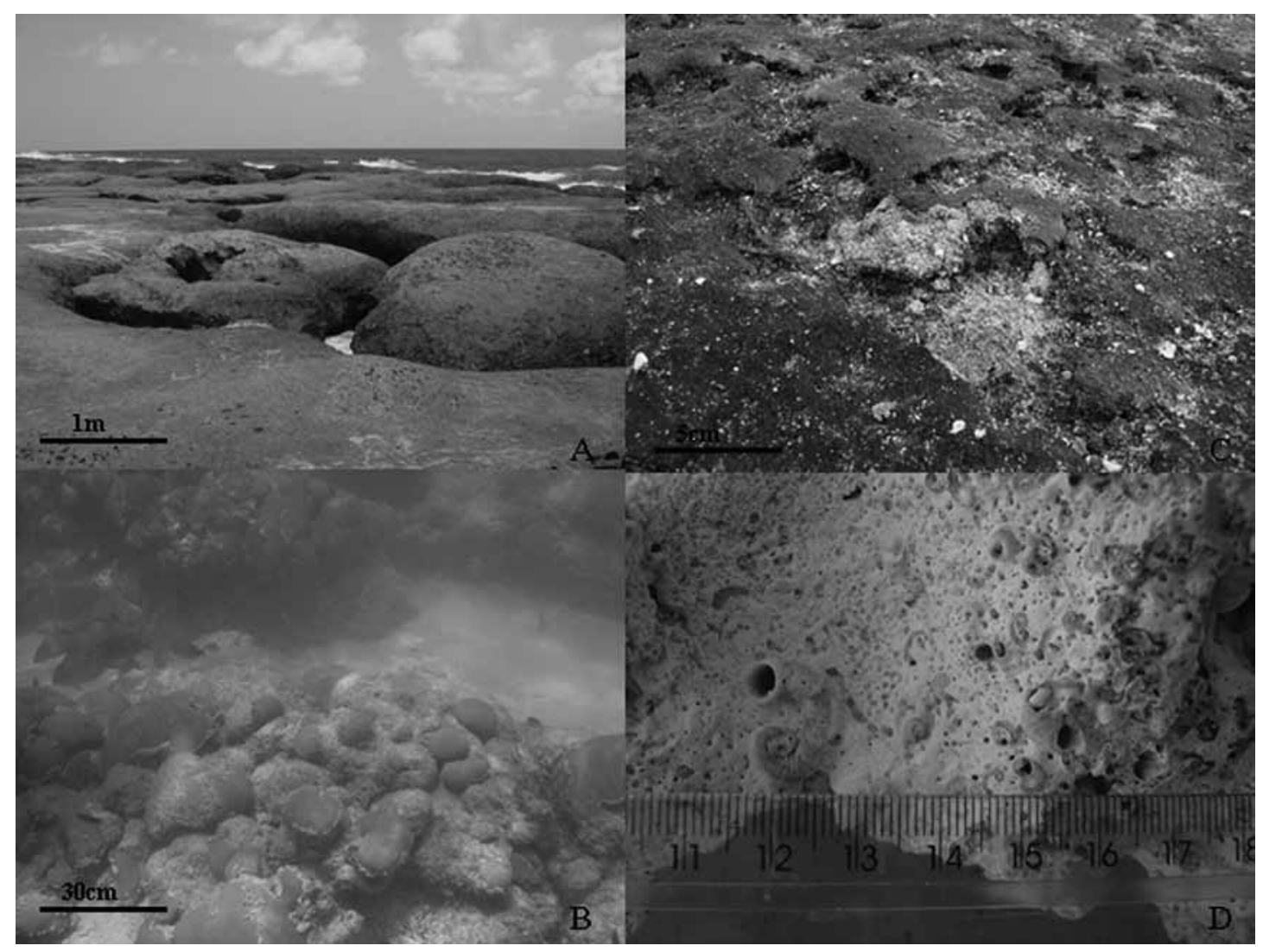

Figura 7 - Aspectos biogeomorfológicos no Atol das Rocas mostrando aspectos da bioconstrução, bioerosão e formação de biofilmes sobre sedimentos carbonáticos bioclásticos. A) Anel recifal bioconstruido (a barlavento) principalmente pela alga calcárea Porolython pachydermum. B) Recife em mancha formado principalmente pela bioconstrução do coral Siderastrea stellata. C) Formação de biofilmes sobre sedimentos carbonáticos na Ilha do Farol. D) Marcas de bioerosão de poliquetas/sipunculídeos (formas arredondadas menores) em amostras do recife do Atol das Rocas, Atlântico sul Ocidental. 
observando-se a ausência do depósito arenoso.

Ao longo do depósito arenoso a planície de sedimento inconsolidado é interrompida pela presença de cristas algáceas. Biogeomorfologicamente observa-se a presença da alga calcárea Porolython pachydermum e de vermetídeos como bioconstrutores. Cnidários como Favia gravida, Zoanthus sociatus e Porites sp. atuam na bioproteção e na bioconstrução desta crista algálica. Importantes processos de bioturbação nos sedimentos são gerados por poliquetas (Fig. 6D), nematódeos e moluscos que vivem neste sedimento constituindo a infauna bentônica.

Canais No anel recifal podem ser encontradas interrupções que comunicam a parte interna do atol com o seu entorno. Tais interrupções são denominadas de barretas ou canais de passagem. Há dois canais principais no Atol das Rocas um situado na parte $\mathrm{W}$ do atol, próxima à ilha do Farol e outra na porção N do anel recifal (Kikuchi 2002; Soares et al. 2009; Pereira et al. 2010).

$\mathrm{O}$ canal próximo à ilha do Farol é menor, com profundidade aproximada de $4 \mathrm{~m}$, sendo conhecido como Barretinha. $\mathrm{O}$ fundo deste canal é de sedimento calcário bioclástico.

$\mathrm{O}$ canal maior encontra-se na porção $\mathrm{N}$ do anel recifal sendo denominado de Barreta Grande. A largura atinge $100 \mathrm{~m}$ e a profundidade varia de $4 \mathrm{~m}$ (laguna) até $10 \mathrm{~m}$ (limite externo do canal). Este canal é formado por espaços entre colunas recifais com paredes verticalizadas. Em amostras recifais observa-se intensa bioerosão ocasionada por poliquetas e sipunculídeos (Fig. 7D). O fundo deste canal é recoberto com sedimento bioclástico areno-cascalhoso onde há intensa bioturbação de organismos da infauna bentônica, principalmente poliquetas.

Piscinas No platô recifal ocorrem descontinuidades denominadas de piscinas. Tais piscinas constituem depressões no platô recifal (Pereira et al. 2010). As piscinas localizam-se em toda a extensão do platô. As profundidades variam de cerca de 1 a 5 metros. Andrade (1959) denominou as bordas das piscinas como bordas "em pala de boné", conhecidas em países de língua inglesa como overhangs. Tais bordas são comumente projeções do topo recifal como bordas de telhados (beirais salientes) (Fig. 5D). As piscinas possuem ligação com à parte externa do recife. O preenchimento do fundo é feito com sedimento arenoso e, nas maiores piscinas, encontram-se colunas recifais isoladas.

Nas piscinas é comum a presença de recifes em mancha ("patch reefs"), de dimensões variadas, ocorrendo em toda a sua extensão (Fig. 7B). A cobertura de bioproteção inclui algas pardas, vermelhas e verdes, além de corais escleractíneos e zoantídeos (Zoanthus sociatus e Palythoa caribaeorum). O peixe Acanthurus chirurgus é comum nesta zona geomorfológica do Atol das Rocas atuando de maneira indireta na bioerosão do recife (Fig. 6A).

Ilhas Arenosas Ilhas arenosas estão localizadas à sotavento no interior do anel do Atol das Rocas, representando os únicos locais que ficam descobertos durante a preamar. Tais ilhas arenosas constituem as partes constantemente emersas, sendo denominadas de ilha do Farol e a do Cemitério. Tais compartimentos biogeomorfológicos são influenciados pela ação dos ventos, marés, correntes, ondas, biota marinha e terrestre.

A Ilha do Cemitério tem a forma aproximada de um trapézio, segundo observações de campo e de imagens aéreas, sendo que sua base maior é voltada para NE. A base maior tem medição aproximada de 400 $\mathrm{m}$ e a altura de $100 \mathrm{~m}$. Seu contorno é delimitado por um depósito de praia, e por um afloramento de calcarenito de praia. A altura máxima da ilha em relação à superfície média do topo do recife é de pouco mais de $3 \mathrm{~m}$. A Ilha do Farol é mais alongada, com a forma de um anzol, segundo Kikuchi (2002). Seu comprimento e largura máxima são de 800 e $300 \mathrm{~m}$, respectivamente.

$\mathrm{Na}$ ilha do Farol pode-se observar o crescimento do esporão que se dá no sentido SW permitindo a formação de uma "baía" ou "enseada" que pode ser caracterizada como um canal de maré, principalmente na porção proximal com presença de "ripple marks" na parte inicial. As laterais são cobertas com Sesuvium portucalastrum e Portulaca oleracea que estabiliza as paredes dos taludes impedindo o processo erosivo. Observam-se recifes de calcarenito com baixo grau de diagênese com cimentação bem recente propiciada pelo fluxo de marés e sedimentação. No sedimento observase a presença de cascalho com coloração marrom-escura (semelhante à área próxima ao terraço de abrasão da ilha do Cemitério e da área a barlavento) introduzido na área antes da formação do esporão de agradação (com o fechamento o material ficou retido).

O sedimento transportado é colonizado de início por cianobactérias, que aceleram a estabilização da areia nas ilhas arenosas. Em seguida instala-se a beldroega, capaz de suportar a semi-imersão nas marés altas, que ajuda a segurar a areia trazida pelo vento, o que faz a ilha crescer aos poucos. A planta Cyperus ligularis é comum nas ilhas sendo fundamental biogeomorfologicamente na fixação das ilhas arenosas e atenuando os processos erosivos (Fig. 6C).

A introdução de Nitrogênio e Fósforo decorrente do guano da avifauna e da matéria orgânica morta eleva a produtividade da área com crescimento de algas clorofíceas, bactérias e grandes áreas com biofilmes de microorganismos sobre uma camada sedimentar de areia carbonática biogênica (Fig. 7C). Pode-se observar uma zona anóxica com baixo grau de decomposição bacteriana aeróbia. Os próprios biofilmes podem agir biogeomorfologicamente protegendo a estrutura de intemperismo e atividade erosiva.

Laguna Na porção NE da região central do recife, adjacente ao anel recifal no seu limite N, e ao depósito arenoso, pelo $\mathrm{S}$ ocorre a presença de uma laguna (Kikuchi 2002; Soares et al. 2009; Pereira et al. 2010). Diferentemente do depósito arenoso a lâmina d'água é persistente sendo submersa. Ocorre a presença de colunas recifais e sedimentos arenosos bioclásticos e cascalhosos. A profundidade máxima varia de acordo com as marés, sendo, nas de sizígia, a variação de, aproxima- 
damente, 4 a $6 \mathrm{~m}$. Nas colunas recifais há forte papel de bioconstrução onde foram observados corais escleractíneos das espécies Montastrea cavernosa, Siderastrea stellata, Porites sp. e algas calcáreas.

CONCLUSÕES Os diferentes compartimentos geoambientais do Atol das Rocas, Atlântico Sul, são afetados por diferentes processos biogeomorfológicos como controle de processos erosivos, bioproteção, bioerosão recifal, bioturbação, cimentação de areia carbonática biogênica, produção de sedimentos biodetríticos e bioconstrução (principalmente de algas calcáreas, vermetídeos e foraminíferos). Organismos diversos incluindo aves, tartarugas, corais, algas, moluscos, poliquetas, angiospermas, foraminíferos e microorganismos agem nos diferentes grupos de processos biogeomorfológicos gerando as características únicas do único Atol do Atlântico Sul Equatorial.
Agradecimentos O presente artigo fez parte da tese de doutorado do programa de Pós-Graduação em Geociências da Universidade Federal do Rio Grande do Sul (UFRGS) intitulada "Geobiologia do Atol das Rocas, Atlântico Sul". M.O Soares agradece ao CNPq (Conselho Nacional de Pesquisa e Desenvolvimento Científico) pela concessão de bolsa de Doutorado. R.K.P. Kikuchi recebe bolsa de pesquisa PQ2 do CNPq. A PETROBRAS e a Fundação SOS Mata Atlântica pelo financiamento da pesquisa dos trabalhos de campo no Atol. Ao ICMBIO (Instituto Chico Mendes de Conservação da Biodiversidade) pela concessão de licença de pesquisa (número 12228-1) e apoio nas atividades de campo (principalmente à Maurizélia Brito; coordenadora da Reserva Biológica (REBIO) Atol das Rocas). Ao Biólogo Carlos Augusto Oliveira Meirelles pelo auxílio na coleta e fotografias subaquáticas.

\section{Referências}

Andrade G.O. 1959. O recife anular das Rocas (Um registro das recentes variações eustáticas no Atlântico equatorial). Anais da Associação dos Geógrafos Brasileiros, 11: 29-61.

Echeverría C.A. \& Pires D.O. 1997. Cnidarians of the Atol das Rocas. In: Proc. $8^{\text {th }}$. Int. Coral Reef Symposium,1, $736 \mathrm{p}$.

Gherardi D.F.M. \& Bosence D.W.J. 1999. Modeling of the ecological succession of encrusting organisms in recent coralline-algal frameworks from Atol das Rocas, Brazil. Palaios, 14:145-158.

Gherardi D.F.M. \& Bosence D.W.J. 2005. Late Holocene Reef growth and relative sea-level changes in Atol das Rocas, equatorial South Atlantic. Coral Reefs, 24: 264272.

Guilcher A. 1988. Coral reef geomorphology. $1^{\text {a }}$ ed., John Wiley \& Sons., 228 p.

Kikuchi R.K.P. 2002. Atol das Rocas, Litoral do Nordeste do Brasil - Único atol do Atlântico Sul Equatorial Ocidental. In: Schobbenhaus C., Campos D.A., Queiroz E.T., Winge M., Berbert-Born M.L.C. (eds.) Sitios Geológicos e Paleontológicos do Brasil. Brasília, DNPM/CPRM, p.379-390.

Kikuchi R.K.P. \& Leão Z.M.A.N. 1997. Rocas (Southwestern Equatorial Atlantic, Brazil): an atoll built primarily by coralline algae. In: Proc. $8^{\text {th }}$. Int. Coral Reef Symposium, 1, $736 \mathrm{p}$.

Larrazábal M.E. \& Oliveira V.S. 2003. Thecosomota e Gymnosomota (Mollusca, Gastropoda) da cadeia Fernando de Noronha, Brasil. Revista Brasileira de Zoologia, 20:351-360.

Mabesoone J.M. \& Coutinho P.N. 1970. Litoral and shallow marine geology of Northeastern Brazil. Trabalhos do
Instituto Oceanográfico Universidade Federal de Pernambuco, 12:1-214.

Naylor L.A., Viles H.A., Carter N.E.A. 2002. Biogeomorphology revisited: looking towards the future. Geomorphology, 47: 3-14.

Naylor L.A. 2005. The Contributions of biogeomorphology to emerging field of geobiology. Palaeogeography, Palaeoclimatology, Palaeoecology, 219: 35-51.

Nimer E. (1989). Climatologia do Brasil. Rio de Janeiro, Instituto Brasileiro de Geografia e Estatística, 421p.

Ottman F. 1963. "L'atol das Rocas" dans l'Atlantique sud tropical. Revue de Géographie Physique et de Géologie Dinamique, 2:101-107.

Pereira N.S., Manso V.A.V., Silva A.M.C., Silva M.B. 2010. Mapeamento Geomorfológico e Morfodinâmica do Atol das Rocas, Atlântico Sul. Revista da Gestão Costeira Integrada, 10(3):331-345.

Schobbernhares C. (ed.) 1984. Geologia do Brasil. Ministério das Minas e Energia, Departamento Nacional de Produção Mineral, Brasília, 501 p.

Soares M.O., Lemos V.B., Kikuchi R.K.P. 2009. Atol das Rocas, Atlântico Sul Equatorial: considerações sobre a classificação do recife biogênico. Revista Brasileira de Geociências, 39:238-243.

Spencer T. \& Viles H. 2002. Bioconstruction, bioerosion and disturbance on tropical coasts: coral reefs and rocky limestone shores. Geomorphology, 48:23-50.

Vallaux C. 1940. La formation atollienne de Rocas (Brésil). Bulletin de L'Institut Océanographique, 37:1-8.

Manuscrito ID 13341

Submetido em 26 de janeiro de 2009 Aceito em 17 de dezembro de 2010 